OPEN ACCESS

Edited by:

Jose Luis Iriarte,

Austral University of Chile, Chile

Reviewed by:

Soizick Le Guyader,

Institut Français de Recherche pour

l'Exploitation de la Mer

(IFREMER), France

*Correspondence:

Marcos Mateus

marcos.mateus@tecnico.ulisboa.pt

Specialty section:

This article was submitted to

Marine Fisheries, Aquaculture and

Living Resources,

a section of the journal

Frontiers in Marine Science

Received: 18 February 2021

Accepted: 09 April 2021

Published: 10 May 2021

Citation:

Mateus $M$, Remondes $M$, Pinto $L$ and Silva A (2021) Monitoring

SARS-CoV-2 as a Microbiological Risk in Shellfish Aquaculture.

Front. Mar. Sci. 8:669402. doi: 10.3389/fmars.2021.669402

\section{Monitoring SARS-CoV-2 as a Microbiological Risk in Shellfish Aquaculture}

\author{
Marcos Mateus ${ }^{1 *}$, Miguel Remondes ${ }^{2}$, Lígia Pinto ${ }^{1}$ and Alexandra Silva ${ }^{3}$ \\ ${ }^{1}$ Marine, Environment and Technology Centre/Laboratory for Robotics and Engineering Systems (MARETEC/LARSyS), \\ Instituto Superior Técnico, Universidade de Lisboa, Lisbon, Portugal, ${ }^{2}$ Instituto de Medicina Molecular João Lobo Antunes, \\ Faculdade de Medicina, Universidade de Lisboa, Lisbon, Portugal, ${ }^{3}$ IPMA, I.P-Instituto Português do Mar e da Atmosfera, \\ Lisbon, Portugal
}

Keywords: SARS-CoV-2, COVID-19, gastrointestinal infection, transmission, shellfish safety, early warning systems

\section{INTRODUCTION}

Coronaviruses $(\mathrm{CoVs})$ are a large family of viruses known to induce respiratory and gastrointestinal (GI) infection in animals and humans. These viruses are persistent in the environment (Guillier et al., 2020; Ren et al., 2020), and known to resist the (mild) food production processes routinely used to inactivate or control bacterial pathogens (Goli, 2020). Until recently, CoVs were not assumed to be highly pathogenic in humans (Zaki et al., 2012), but this perception changed after the recent Severe Acute Respiratory Syndrome CoV (SARS-CoV), Middle East Respiratory Syndrome $\mathrm{CoV}$ (MERS-CoV), and the current severe acute respiratory syndrome (SARS-CoV-2) outbreaks.

The most recently identified coronavirus, SARS-CoV-2, first isolated in late December 2019 among patients with severe pneumonia at Wuhan City, China (Zhu et al., 2020), revealed a significant gap in knowledge about CoVs. Since then, scientists have been trying to understand its transmission pathways and infection dynamics, and how the virus shapes the resulting pathology, the coronavirus disease (COVID-19). A significant number of scientific breakthroughs related to SARS-CoV-2 have been published over the past year, but there are still many unknows and unanswered questions, and countless others will surely arise as new data is collected, and new strains revealed.

So far, the contribution of foodborne transmission for the maintenance and recurrence of SARSCoV-2 infection is still disputed (Amirian, 2020; Donà et al., 2020; Li et al., 2021). Such possibility, however, should be considered as an emerging risk with potential public health impact, demanding the implementation, or adaptation, of effective strategies to protect at-risk populations in the face of emerging epidemiologic data.

Shellfish are particularly relevant in such assessment. Often consumed uncooked, shellfish are a long-standing source of foodborne illness, frequently associated with foodborne outbreaks with substantial impact on human health (Jones, 2009). For instance, norovirus (NoV) accumulation by shellfish, and the ensuing risks to human health associated with shellfish consumption are well-documented (Bellou et al., 2013). Similarly, the accumulation of other infectious agents of human-associated waste sources, and its repercussion on human health, is well-reported (Fleming et al., 2014).

Facing a hypothetical foodborne transmission of COVID-19 via the consumption of raw shellfish, we briefly address possible reasons to consider the incorporation of SARS-CoV-2 detection strategies on regular shellfish monitoring programs and include this risk on early warning 
systems to the aquaculture industry and public health. Our opinion is based on current knowledge about the SARS-CoV2 and long-established facts about the role of wastewater and shellfish on the transmission of viral infections to humans (Figure 1).

\section{SARS-COV-2 AND GASTROINTESTINAL FUNCTION IN HUMANS}

Though the respiratory system is most severely impacted by $\mathrm{CoVs}$, these viruses are found in the sweat glands, kidney, and intestinal tract, and therefore may spread via sweat, urine, and fecal excretion (Ding et al., 2004). In addition, their presence in the alimentary tract (Huang et al., 2021), suggests that this is an entry route for viruses present in food or water.

Information about other potential pathways of SARS-CoV2 transmission is relatively scarce, but there is accumulating evidence in support of fecal-mediated transmission (Amirian, 2020; Cuicchi et al., 2021; Heneghan et al., 2021). SARS-CoV2 GI tract infection has been repeatedly reported (Guan et al., 2020; Hindson, 2020; Lo et al., 2020; Mao et al., 2020; Pan et al., 2020; Xiao et al., 2020). Accordingly, viable viruses were detected in feces, implicating these as a potential source of SARSCoV-2 transmission by fecal contamination (Wang et al., 2020). Paradoxically, some studies also infer that most of the viral particles excreted in feces are no longer infectious (Walsh et al., 2020; Senatore et al., 2021).

A recent study in children found that positive detection of SARS-CoV-2 on rectal swabs outlasts even negative nasopharyngeal testing, suggesting that the GI tract might be the primary apparatus to be infected, with higher incidence of fecal-oral transmission (Xu et al., 2020). SARS-CoV-2 was also recovered from nasal washes, saliva, urine, and feces of infected animals (ferrets) up to 8 days post-infection (Kim et al., 2020). Thus, while still poorly understood, the GI symptoms reported from the start of COVID-19 epidemic at least suggest that fecal-oral transmission of SARS-CoV-2 may occur (Yeo et al., 2020).

\section{THE PRESENCE OF VIRUSES IN SEWAGE}

NoV enter aquatic environments by contaminated overland runoff after heavy rainfall, hydraulic overload in sewage treatment plants, and combined sewer overflow (Kim et al., 2016). These routes are shared by most other pathological agents. The presence of SARS-CoV-2 in wastewater, reported worldwide, suggests that this may also be the case for this infectious agent (La Rosa et al., 2020; Mallapaty, 2020; Medema et al., 2020; Wu et al., 2020).

Early studies showed that coronaviruses rapidly become inactive in wastewater (Sherchan et al., 2020), but can remain infectious up to 4 days if contained within fecal matter (Gundy et al., 2009). Recent assessments agree with these observations, reporting that the virus can survive hours to days in untreated wastewater (Arslan et al., 2020; Orive et al., 2020; Kumar et al., 2021; Patel et al., 2021), and even much longer periods in cold climates (Bhowmick et al., 2020). Studies have reported that SARS-CoV-2 remains active for 25 days in wastewater at $5^{\circ} \mathrm{C}$
(Shutler et al., 2021) and can persist in wastewater at room temperature for $\sim 6$ days (Bivins et al., 2020).

\section{DISCUSSION}

The evidence reviewed here suggests the possibility of fecaloral transmission of SARS-CoV-2. If confirmed, the novel CoV can share foodborne infection pathways with other CoVs, and even NoV (Lopman et al., 2012; Li et al., 2021). Shellfish such as oysters can selectively accumulate NoV strains as they have human-like viral carbohydrate ligands (Le Guyader et al., 2012). If indeed this, or a similar, process is shared by SARS-CoV-2, then shellfish can potentially act as a vector for fecal-oral transmission to humans, similarly, and even concurrently, to norovirus, with the predictable devastating consequences (Figure 1).

Due to significant knowledge gaps, the potential role of wastewater in SARS-CoV-2 transmission has been underappreciated (Kitajima et al., 2020; Lodder and de Roda Husman, 2020), and little is known about the infective power of SARS-CoV-2 particles found in sewage waters. Respiratory droplets are the main human-to-human mechanism of transmission, but fecal shedding with environmental contamination is increasingly seen as having an important role in viral spread (Bhowmick et al., 2020; Donà et al., 2020).

Until now, the viability of SARS-CoV-2 in wastewater has not been proven (Senatore et al., 2021), and further studies are needed to investigate its fate in wastewater (Collivignarelli et al., 2020) and in natural water bodies receiving treated or untreated wastewater (Kumar et al., 2021). The WHO, for instance, assumes that it is unlikely that wastewater will become an important transmission pathway for coronaviruses like SARS-CoV-2 (WHO/UNICEF, 2020). However, ruling out such possibility at such early stage may prove disastrous, as SARS$\mathrm{CoV}-2$ remains viable for significantly longer periods in stool samples than in respiratory and serum samples. Such resilience highlights the need to strengthen the public management of sewage waters in the prevention and control of the epidemic (Zheng et al., 2020; Senatore et al., 2021).

A recent monitoring study made in several sites along the coast of France reported the absence of SARS-CoV-2 in oysters (Desdouits et al., 2021). The authors, nonetheless, do not exclude shellfish as potential agents of transmission, but highlight the need for more monitoring studies before reaching such conclusion. Food industry and regulatory agencies should take such knowledge into account, despite its preliminary stage, to regulate and implement food safety principles and practices that prevent the spread of SARS-CoV-2 via shellfish consumption, all the while protecting the economy and livelihood of human populations therein dependent.

Given the high infection and rapid transmission of SARSCoV-2 (Kim et al., 2020), shellfish commerce and consumption can rapidly and effectively propagate infection over long distances, and sustain its endemic persistence. To prevent such occurrence, the following questions must necessarily be addressed and unequivocally answered as part of an integrative approach to mitigate COVID-19: 


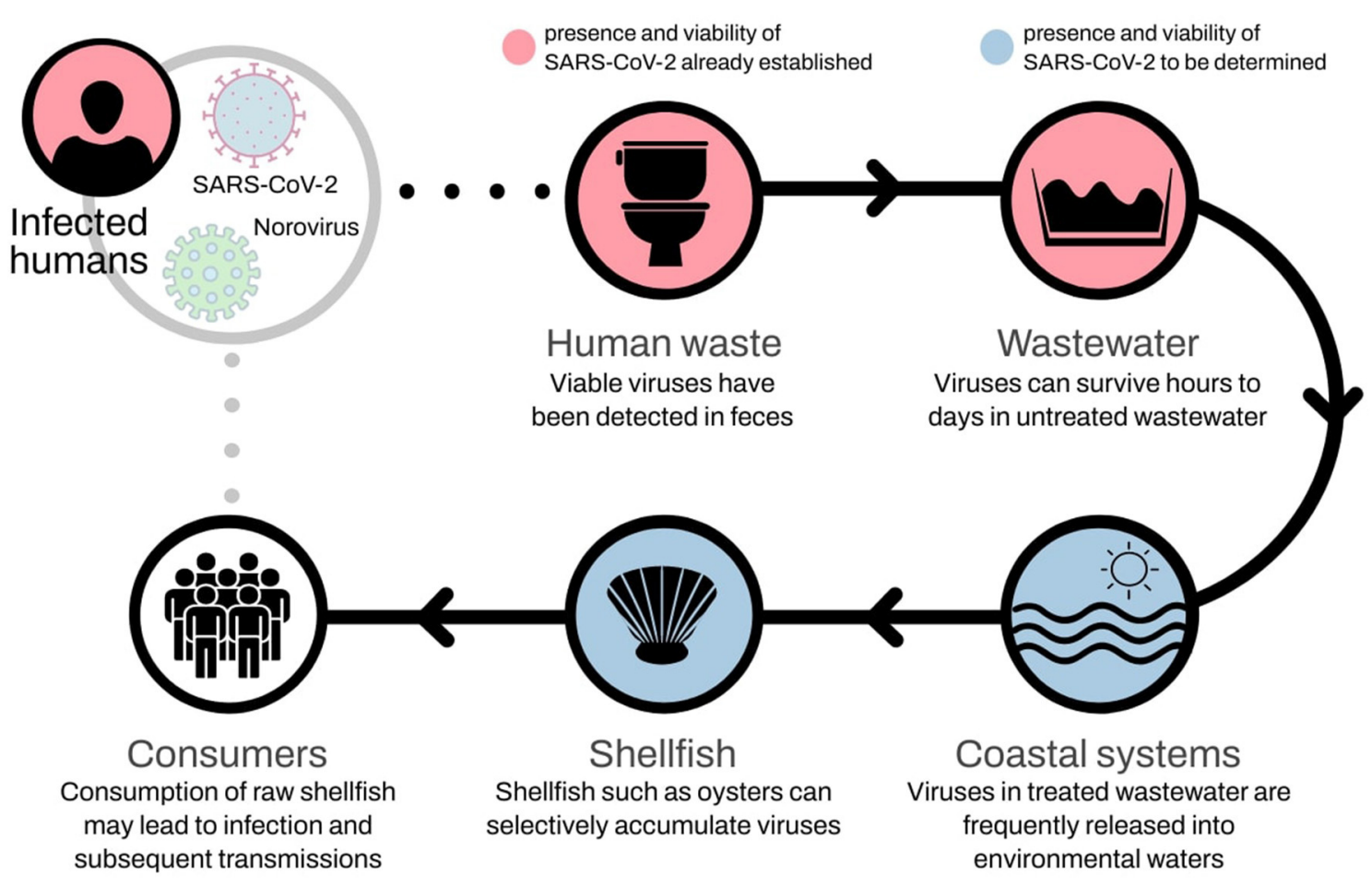

FIGURE 1 | Potential foodborne transmission of SARS-CoV-2 via shellfish. Such transmission route is known to occur with norovirus.

1. Is SARS-CoV-2 found in coastal waters, under the influence of urban pollution, still infectious?

2. Are shellfish production/growth conditions and practices (e.g., in oyster beds) enough to allow environmental factors such as osmotic stress in salt water, and UV radiation, to inactivate the virus?

3. Do shellfish accumulate SARS-CoV-2 as they do NoV?

4. If SARS-CoV-2 is found in shellfish:

a. Is it still viable to infect humans (making shellfish a vector of contamination)?

b. Is the source environmental or from being handled by infected people (good hygiene practices must be in place)?

c. Can it be eradicated by depuration?

5. Should government or the regulatory authorities consider a temporary suspension of production and/or commercialization of shellfish before the answers to the above questions are reached?

Seafood-born infection and toxicity is presently met by effective good-practices in most developed countries. The current COVID-19 epidemic threatens to be a "game-changer" to the effect that failing to address the topics discussed here might perpetuate the threat of infection, albeit in a much smaller scale than by direct contact with infected humans, but still, one capable of triggering an outbreak of serious consequences. SARS-CoV2 transmission via shellfish unfolds over multiple spatial scales, as freshly harvested products can be consumed locally, but also commercialized world-wide. Oysters pose a particular threat, as they are one of the most commercialized group of shellfish over the past few years (FAO, 2020), and they are often consumed raw.

For the time being, the possibility of transmission through the food sector is considered negligible, and its assessment is not seen as a priority by public authorities (Bilal et al., 2020; Rizou et al., 2020). However, until such hypothesis is discarded, there are reasons to consider the inclusion of SARS-CoV-2 in monitoring programs and early warning systems currently implemented in the shellfish industry. We note, nonetheless, that economic consequences may be expected if bans to shellfish harvesting and consumptions arise from such policies, impacting different sectors of activity, from artisanal shellfish harvesters, to aquaculture producers, and ultimately across all levels of shellfish industry.

Finally, the above considerations are pertinent, not just to shellfish, but also to other food sources at risk of contamination with liquid or solid human waste potentially carrying SARS-CoV-2.

\section{AUTHOR CONTRIBUTIONS}

MM and MR contributed equally to the design and development of the manuscript. LP provided insights on early warning systems for the aquaculture sector. AS contributed with expertise on monitoring programs and early warning systems for shellfish areas. LP and AS were actively involved in the manuscript preparation. All authors contributed to the article and approved the submitted version. 


\section{FUNDING}

This work was supported by the Interreg Atlantic Area Operational Programme, Grant Agreement No: EAPA 182/2016 (Project PRIMROSE, https://www.shellfish-

\section{REFERENCES}

Amirian, E. S. (2020). Potential fecal transmission of SARS-CoV-2: current evidence and implications for public health. Int. J. Infect. Dis. 95, 363-370. doi: 10.1016/j.ijid.2020.04.057

Arslan, M., Xu, B., and Gamal El-Din, M. (2020). Transmission of SARS-CoV2 via fecal-oral and aerosols-borne routes: environmental dynamics and implications for wastewater management in underprivileged societies. Sci. Total Environ. 743:140709. doi: 10.1016/j.scitotenv.2020.140709

Bellou, M., Kokkinos, P., and Vantarakis, A. (2013). Shellfish-borne viral outbreaks: a systematic review. Food Environ. Virol. 5, 13-23. doi: 10.1007/s12560-012-9097-6

Bhowmick, G. D., Dhar, D., Nath, D., Ghangrekar, M. M., Banerjee, R., Das, S., et al. (2020). Coronavirus disease 2019 (COVID-19) outbreak: some serious consequences with urban and rural water cycle. NPJ Clean Water 3:32. doi: 10.1038/s41545-020-0079-1

Bilal, M., Nazir, M. S., Rasheed, T., Parra-Saldivar, R., and Iqbal, H. M. N. (2020). Water matrices as potential source of SARS-CoV-2 transmission - an overview from environmental perspective. Case Stud. Chem. Environ. Eng. 2:100023. doi: $10.1016 /$ j.cscee.2020.100023

Bivins, A., Greaves, J., Fischer, R., Yinda, K. C., Ahmed, W., Kitajima, M., et al. (2020). Persistence of SARS-CoV-2 in water and wastewater. Environ. Sci. Technol. Lett. 7, 937-942. doi: 10.1021/acs.estlett.0c00730

Collivignarelli, M. C., Collivignarelli, C., Carnevale Miino, M., Abbà, A., Pedrazzani, R., and Bertanza, G. (2020). SARS-CoV-2 in sewer systems and connected facilities. Process Saf. Environ. Prot. 143, 196-203. doi: 10.1016/j.psep.2020.06.049

Cuicchi, D., Lazzarotto, T., and Poggioli, G. (2021). Fecal-oral transmission of SARS-CoV-2: review of laboratory-confirmed virus in gastrointestinal system. Int. J. Colorectal Dis. 36, 437-444. doi: 10.1007/s00384-020-03785-7

Desdouits, M., Piquet, J.-C., Wacrenier, C., Le Mennec, C., Parnaudeau, S., Jousse, S., et al. (2021). Can shellfish be used to monitor SARSCoV-2 in the coastal environment? Sci. Total Environ. 778:146270. doi: 10.1016/j.scitotenv.2021.146270

Ding, Y., He, L., Zhang, Q., Huang, Z., Che, X., Hou, J., et al. (2004). Organ distribution of severe acute respiratory syndrome (SARS) associated coronavirus (SARS-CoV) in SARS patients: implications for pathogenesis virus transmission pathways. J. Pathol. 203, 622-630. doi: 10.1002/path.1560

Donà, D., Minotti, C., Costenaro, P., Da Dalt, L., and Giaquinto, C. (2020). Fecaloral transmission of SARS-CoV-2 in children: is it time to change our approach? Pediatr. Infect. Dis. J. 39, e133-134. doi: 10.1097/INF.0000000000002704

FAO (2020). FAO - Fisheries and Aquaculture Information and Statistics Branch. Available at: http://www.fao.org/fishery/statistics/en (accessed May 7, 2020).

Fleming, L. E., McDonough, N., Austen, M., Mee, L., Moore, M., Hess, P., et al. (2014). Oceans and human health: a rising tide of challenges and opportunities for Europe. Mar. Environ. Res. 99, 16-19. doi: 10.1016/j.marenvres.2014.05.010

Goli, M. (2020). Review of novel human $\beta$-coronavirus (2019-nCoV or SARS$\mathrm{CoV}-2$ ) from the food industry perspective-appropriate approaches to food production technology. Food Sci. Nutr. 8, 5228-5237. doi: 10.1002/fsn3.1892

Guan, W., Ni, Z., Hu, Y., Liang, W., Ou, C., He, J., et al. (2020). Clinical characteristics of coronavirus disease 2019 in China. N. Engl. J. Med. 382, 1708-1720. doi: 10.1056/NEJMoa2002032

Guillier, L., Martin-Latil, S., Chaix, E., Thébault, A., Pavio, N., Le Poder, S., et al. (2020). Modeling the inactivation of viruses from the coronaviridae family in response to temperature and relative humidity in suspensions or on surfaces. Appl. Environ. Microbiol. 86, e01244-e01220. doi: 10.1128/AEM.01244-20

Gundy, P. M., Gerba, C. P., and Pepper, I. L. (2009). Survival of coronaviruses in water and wastewater. Food Environ. Virol. 1:10. doi: $10.1007 /$ s12560-008-9001-6 safety.eu). AS supported by Grant IPMA-BCC-201635 from project SNMxB-Monitor-16.02.01-FEAMP-0043. Publication fees were supported by FCT/MCTES (PIDDAC) through project LARSyS-FCT Pluriannual funding 2020-2023 (UIDB/EEA/50009/2020).

Heneghan, C., Spencer, E. A., Brassey, J., and Jefferson, T. (2021). SARS-CoV-2 and the role of orofecal transmission: systematic review. F1000Research 10:231. doi: 10.1101/2020.08.04.20168054

Hindson, J. (2020). COVID-19: faecal-oral transmission? Nat. Rev. Gastroenterol. Hepatol. 17:259. doi: 10.1038/s41575-020-0295-7

Huang, N., Pérez, P., Kato, T., Mikami, Y., Okuda, K., Gilmore, R. C., et al. (2021). SARS-CoV-2 infection of the oral cavity and saliva. Nat. Med. doi: 10.1038/s41591-021-01296-8. [Epub ahead of print].

Jones, S. (2009). "1 - Microbial contamination and shellfish safety," in Woodhead Publishing Series in Food Science, Technology and Nutrition, eds S. E. Shumway and G. E. Rodrick (Cambridge: Woodhead Publishing), 3-42.

Kim, M. S., Koo, E. S., Choi, Y. S., Kim, J. Y., Yoo, C. H., Yoon, H. J., et al. (2016). Distribution of human norovirus in the coastal waters of South Korea. PLoS ONE 11:e0163800. doi: 10.1371/journal.pone.0163800

Kim, Y. I., Kim, S. G., Kim, S. M., Kim, E. H., Park, S. J., Yu, K. M., et al. (2020). Infection and rapid transmission of SARS-CoV-2 in ferrets. Cell Host Microbe 27, 704-709. doi: 10.1016/j.chom.2020.03.023

Kitajima, M., Ahmed, W., Bibby, K., Carducci, A., Gerba, C. P., Hamilton, K. A., et al. (2020). SARS-CoV-2 in wastewater: state of the knowledge and research needs. Sci. Total Environ. 739:139076. doi: 10.1016/j.scitotenv.2020. 139076

Kumar, M., Alamin, M., Kuroda, K., Dhangar, K., Hata, A., Yamaguchi, H., et al. (2021). Potential discharge, attenuation and exposure risk of SARS-CoV-2 in natural water bodies receiving treated wastewater. NPJ Clean Water 4:8. doi: 10.1038/s41545-021-00098-2

La Rosa, G., Iaconelli, M., Mancini, P., Bonanno Ferraro, G., Veneri, C., Bonadonna, L., et al. (2020). First detection of SARS-CoV-2 in untreated wastewaters in Italy. Sci. Total Environ. 736:139652. doi: 10.1016/j.scitotenv.2020.139652

Le Guyader, F. S., Atmar, R. L., and Le Pendu, J. (2012). Transmission of viruses through shellfish: when specific ligands come into play. Curr. Opin. Virol. 2, 103-110. doi: 10.1016/j.coviro.2011.10.029

Li, D., Zhao, M. Y., and Hsern, M. T. T. (2021). What makes a foodborne virus: comparison between coronaviruses with human noroviruses. Curr. Opin. Food Sci. 42, 1-7. doi: 10.1016/j.cofs.2020.04.011

Lo, I. L., Lio, C. F., Cheong, H. H., Lei, C. I., Cheong, T. H., Zhong, X., et al. (2020). Evaluation of SARS-CoV-2 RNA shedding in clinical specimens and clinical characteristics of 10 patients with COVID-19 in Macau. Int. J. Biol. Sci. 16, 1698-1707. doi: 10.7150/ijbs.45357

Lodder, W., and de Roda Husman, A. M. (2020). SARS-CoV-2 in wastewater: potential health risk, but also data source. Lancet Gastroenterol. Hepatol. 1253:30087. doi: 10.1016/S2468-1253(20)30087-X

Lopman, B., Gastañaduy, P., Park, G. W., Hall, A. J., Parashar, U. D., and Vinjé, J. (2012). Environmental transmission of norovirus gastroenteritis. Curr. Opin. Virol. 2, 96-102. doi: 10.1016/j.coviro.2011.11.005

Mallapaty, S. (2020). How sewage could reveal true scale of coronavirus outbreak. Nature 580, 176-177. doi: 10.1038/d41586-020-00973-x

Mao, R., Liang, J., Shen, J., Ghosh, S., Zhu, L. R., Yang, H., et al. (2020). Implications of COVID-19 for patients with pre-existing digestive diseases. Lancet Gastroenterol. Hepatol. 5, 426-428. doi: 10.1016/S2468-1253(20)30076-5

Medema, G., Heijnen, L., Elsinga, G., Italiaander, R., and Brouwer, A. (2020). Presence of SARS-coronavirus-2 RNA in sewage and correlation with reported COVID-19 prevalence in the early stage of the epidemic in The Netherlands. Environ. Sci. Technol. Lett. 7, 511-516. doi: 10.1021/acs.estlett.0c00357

Orive, G., Lertxundi, U., and Barcelo, D. (2020). Early SARS-CoV-2 outbreak detection by sewage-based epidemiology. Sci. Total Environ. 732:139298. doi: 10.1016/j.scitotenv.2020.139298

Pan, L., Mu, M., Yang, P., Sun, Y., Wang, R., Yan, J., et al. (2020). Clinical characteristics of COVID-19 patients with digestive symptoms in Hubei, China: 
a descriptive, cross-sectional, multicenter study. Am. J. Gastroenterol. 11, 766-773. doi: 10.14309/ajg.0000000000000620

Patel, M., Chaubey, A. K., Pittman, C. U., Mlsna, T., and Mohan, D. (2021). Coronavirus (SARS-CoV-2) in the environment: occurrence, persistence, analysis in aquatic systems and possible management. Sci. Total Environ. 765:142698. doi: 10.1016/j.scitotenv.2020.142698

Ren, S.-Y., Wang, W.-B., Hao, Y.-G., Zhang, H.-R., Wang, Z.-C., Chen, Y.-L., et al. (2020). Stability and infectivity of coronaviruses in inanimate environments. World J. Clin. Cases 8, 1391-1399. doi: 10.12998/wjcc.v8.i8.1391

Rizou, M., Galanakis, I. M., Aldawoud, T. M. S., and Galanakis, C. M. (2020). Safety of foods, food supply chain and environment within the COVID-19 pandemic. Trends Food Sci. Technol. 102, 293-299. doi: 10.1016/j.tifs.2020.06.008

Senatore, V., Zarra, T., Buonerba, A., Ho, K., Shadi, C., and Gregory, W. H. (2021). Indoor versus outdoor transmission of SARS - COV - 2 : environmental factors in virus spread and underestimated sources of risk. Euro Mediterranean J. Environ. Integr. 6:30. doi: 10.1007/s41207-021-00243-w

Sherchan, S. P., Shahin, S., Ward, L. M., Tandukar, S., Aw, T. G., Schmitz, B., et al. (2020). First detection of SARS-CoV-2 RNA in wastewater in North America: a study in Louisiana, USA. Sci. Total Environ. 743:140621. doi: 10.1016/j.scitotenv.2020.140621

Shutler, J. D., Zaraska, K., Holding, T., Machnik, M., Uppuluri, K., Ashton, I. G. C., et al. (2021). Rapid Assessment of SARS-CoV-2 Transmission Risk for Fecally Contaminated River Water. ACS EST Water. 1, 949-957. doi: 10.1021/acsestwater.0c00246

Walsh, K. A., Jordan, K., Clyne, B., Rohde, D., Drummond, L., Byrne, P., et al. (2020). SARS-CoV-2 detection, viral load and infectivity over the course of an infection. J. Infect. 81, 357-371. doi: 10.1016/j.jinf.2020.06.067

Wang, W., Xu, Y., Gao, R., Lu, R., Han, K., Wu, G., et al. (2020). Detection of SARS-CoV-2 in different types of clinical specimens. JAMA 323, 1843-1844. doi: 10.1001/jama.2020.3786

WHO/UNICEF (2020). Water, Sanitation, Hygiene and Waste Management for the COVID-19 Virus.

Wu, F., Xiao, A., Zhang, J., Gu, X., Lee, W. L., Kauffman, K., et al. (2020). SARSCoV-2 titers in wastewater are higher than expected from clinically confirmed cases. mSystems 5:e00614-20. doi: 10.1128/mSystems.00614-20
Xiao, F., Tang, M., Zheng, X., Liu, Y., Li, X., and Shan, H. (2020). Evidence for gastrointestinal infection of SARS-CoV2. Gastroenterology 158, 1831-1833.e3. doi: 10.1053/j.gastro.2020. 02.055

Xu, Y., Li, X., Zhu, B., Liang, H., Fang, C., Gong, Y., et al. (2020). Characteristics of pediatric SARS-CoV-2 infection and potential evidence for persistent fecal viral shedding. Nat. Med. 26, 502-505. doi: 10.1038/s41591-0200817-4

Yeo, C., Kaushal, S., and Yeo, D. (2020). Enteric involvement of coronaviruses: is faecal-oral transmission of SARS-CoV-2 possible? Lancet Gastroenterol. Hepatol. 5, 335-337. doi: 10.1016/S2468-1253(20) 30048-0

Zaki, A. M., van Boheemen, S., Bestebroer, T. M., Osterhaus, A. D. M. E., and Fouchier, R. A. M. (2012). Isolation of a novel coronavirus from a man with pneumonia in Saudi Arabia. N. Engl. J. Med. 367, 1814-1820. doi: 10.1056/NEJMoa1211721

Zheng, S., Fan, J., Yu, F., Feng, B., Lou, B., Zou, Q., et al. (2020). Viral load dynamics and disease severity in patients infected with SARS-CoV-2 in Zhejiang province, China, January-March 2020: retrospective cohort study. BMJ 369, m1443. doi: 10.1136/bmj.m1443

Zhu, N., Zhang, D., Wang, W., Li, X., Yang, B., Song, J., et al. (2020). A novel coronavirus from patients with pneumonia in China, 2019. N. Engl. J. Med. 382, 727-733. doi: 10.1056/NEJMoa2001017

Conflict of Interest: The authors declare that the research was conducted in the absence of any commercial or financial relationships that could be construed as a potential conflict of interest.

Copyright (C) 2021 Mateus, Remondes, Pinto and Silva. This is an open-access article distributed under the terms of the Creative Commons Attribution License (CC BY). The use, distribution or reproduction in other forums is permitted, provided the original author(s) and the copyright owner(s) are credited and that the original publication in this journal is cited, in accordance with accepted academic practice. No use, distribution or reproduction is permitted which does not comply with these terms. 